\title{
Energy Performance of Construction Materials Using Waste Recycled Polymer as Fine Aggregate Replacement
}

\author{
Tiziana Cardinale*, Corradino Sposato, Maria Bruna Alba, Andrea Feo, Piero De Fazio
}

ENEA, C.R. Trisaia, Sez. DTE-SAEN, s.s. 106 Jonica km. 419,500 Rotondella, Italy

Corresponding Author Email: tizcardina@ hotmail.it

https://doi.org/10.18280/ijht.370305

Received: 10 May 2019

Accepted: 20 August 2019

\section{Keywords:}

$P V C$ compound, UV-aging, thermal properties, mechanical resistance, ecofriendly materials

\begin{abstract}
Plastic has become an essential part of our modern lifestyle and its global diffusion has led to a significant increase in the production of related waste, with obvious repercussions on the environment and on the entire sustainability chain.

Recycling this kind of materials in the field of civil and industrial engineering is considered an ecological and economical solution due to the advantages it can offer.

This paper represents the results of experimental investigations of mechanical strength, hygrothermal and durability properties of two kinds of products: urban tiles $(90 \%$ PVC powder and $10 \%$ polyurethane resin) and cement-based mortars reinforced with PVC compound coming out of electric cable protective sheath. The manufactured mortars were obtained by the volumetric substitution of the sand with five different percentages of plastic waste, from $10 \%$ to $50 \%$.

Plastic aggregates reduce density, causing a decrease in flexural and compressive strength of mortars. Nevertheless, the presence of plastic aggregate leads to a significant improvement of thermal insulation and shows a greater resistance to capillary water absorption compared to the reference one. The mechanical tests after two different cycles of accelerated solar aging of urban tiles demonstrated the feasibility of its use for external flooring (green parking).

These results foster future studies about the development of increasingly eco-sustainable building materials.
\end{abstract}

\section{INTRODUCTION}

Starting from the research carried out and published in the proceedings of the AIGE IIETA Congress on TI-IJES on June 2019 [1], the following paper allows an extension of the considerations and the tests implemented in the previous study.

Energy sustainability and adaptation to climate change are today the founding elements of our community development policies.

A substantial growth in the consumption of plastic is observed all over the world in recent years, which also implies production of a big amount of plastic-related waste, which are non-biodegradable and represent a serious environmental threat to modern civilization [2-4]. Plastic is composed of several toxic chemicals that can pollute soil, air and water. Land-filling of plastic is also dangerous due to its slow degradation rate and bulky nature [5].

Among polymeric waste particles, polyvinyl chloride (PVC) is a really interesting case [6].

Since the 60s, PVC has been used in many products, and taking into account that its life is around $30-60$ years, its waste is expected to increase in the future [7].

As it is an organic hydrocarbon-based material, its high calorific value can be used for incineration or in other high temperature processes. But, burning of plastics releases a variety of poisonous chemicals into the air, including dioxins, one of the most toxic substances.
There are some studies on the PVC residues treating, by steam gasification or pyrolysis [8], but it is clear that it does not exist an effective and appropriate way to recycle them.

However, they can also be considered as potential "raw second materials", with very advantageous characteristics in terms of conversion and reuse of shares of Gray Energy and GWp (emission of greenhouse gases), because they could effectively reduce the impact of outgoing $\mathrm{CO}_{2}$ and the waste amount to be sent to the landfill [9].

So there is a pressing interest in the ways of recycling these residues in order to preserve natural resources and produce eco-friendly materials. Moreover, energy performance is becoming increasingly important, because of environmental restrictions and rising costs of fuel and energy. These issues have led to the development of appropriate alternative solutions, creating a fast growing sector in modern construction. For this reason, the reuse of PVC powder and granules for new civil engineering applications could be a feasible option for its disposal.

The present paper is focused on the secondary use of PVC compound (obtained from crushing electrical copper cables, whose envelopes are principally formed by such polymer) and its possible incorporation in two different typologies of prototypes: cement-based materials with no structural applications and improved hygro-thermal characteristics (PVC-mortar) and also elements for street furniture, components for anti-shock flooring and/or substrates for ecological islands (PVC-urban tile). 


\section{MATERIALS AND METHODS}

\subsection{PVC-mortar preparation and characterization}

The waste materials used for the cement based samples came from operations carried out at R.ed.el srl that consist of the triturating of "out of use" PVC copper cables (PVC-Cu) through a procedure that allowed the whole segregation of the conductive metal and the polymeric protective coating, producing completely disaggregated and heterogeneous mixture subsequently separated.

In addition to PVC-Cu, adequately sieved [10], the cementitious mixture was composed from Portland cement CEM II/A-LL 32.5 R [11], water at room temperature able to guarantee a water/cement ratio of 0.5 , sand characterized by a particle size composition between 0 and $4 \mathrm{~mm}$ [12].

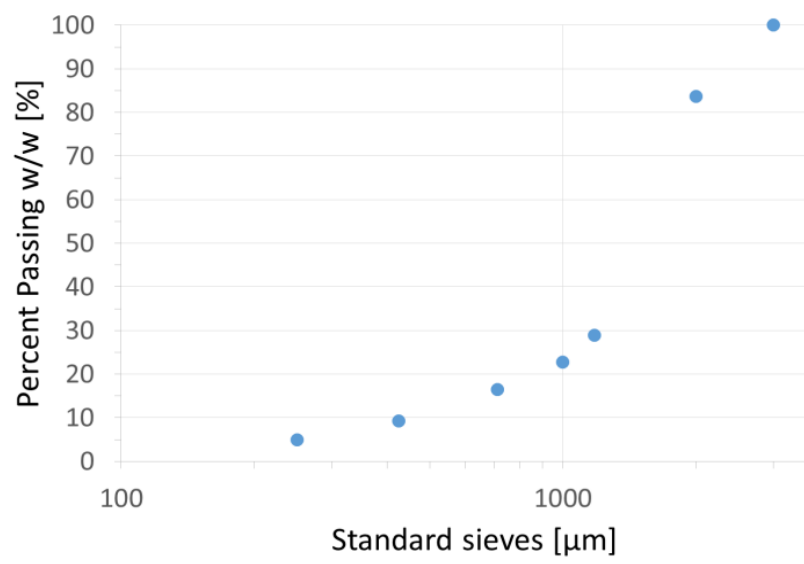

Figure 1. Granulometric distribution of PVC-Cu



Figure 2. $\mathrm{PVC}-\mathrm{Cu}$ sieving results

In order to find the best mix design for the composite material six types of mixtures were produced: the first one, considered as reference (REF), was made only with cement, sand and water, while the other five mixtures, indicated as PVC10, PVC20, PVC30, PVC40 and PVC50, presented a volumetric replacement of the silica aggregate [13] with PVC, respectively equal to $10,20,30,40$ and $50 \%$.

For the experimental tests two sample geometries were prepared: the first one used in order to study mechanical properties [14] and to make capillary water absorption tests (dimensions $160 \times 40 \times 40 \mathrm{~mm}$ ); the second one to measure thermal conductivity (dimensions $29 \times 29 \times 2.45 \mathrm{~mm}$ ) [15].
Table 1. Characteristics of PVC mortars

\begin{tabular}{ccccccc}
\hline & REF & PVC1 & PVC2 & PVC3 & PVC4 & PVC5 \\
& {$[\mathrm{kg}]$} & $\begin{array}{c}0 \\
{[\mathrm{~kg}]}\end{array}$ & $\begin{array}{c}0 \\
{[\mathrm{~kg}]}\end{array}$ & $\begin{array}{c}0 \\
{[\mathrm{~kg}]}\end{array}$ & $\begin{array}{c}0 \\
{[\mathrm{~kg}]}\end{array}$ & {$[\mathrm{kg}]$} \\
\hline PVC & - & 0.35 & 0.28 & 1.05 & 0.56 & 1.76 \\
\hline Cement & 2.51 & 2.51 & 0.56 & 2.51 & 1.00 & 2.51 \\
\hline Sand & 6.76 & 6.09 & 1.20 & 4.73 & 1.62 & 3.38 \\
\hline Water & 1.25 & 1.25 & 0.16 & 1.25 & 0.50 & 1.25 \\
\hline $\begin{array}{c}\text { Density } \\
{\left[\mathrm{kg} / \mathrm{m}^{3}\right]}\end{array}$ & 205 & 1950 & 1870 & 1790 & 1620 & 1650
\end{tabular}

In the first phase curing of the mechanical tests specimens [1] was performed under conditions of constant temperature of $20{ }^{\circ} \mathrm{C} \pm 2{ }^{\circ} \mathrm{C}$ and relative humidity of $95 \% \pm 5 \%$ and then they were taken from the moulds after 24 hours and placed in an environment with controlled humidity of $65 \% \pm 5 \%$ and at a temperature of $20{ }^{\circ} \mathrm{C} \pm 2{ }^{\circ} \mathrm{C}$. A Dual Column Instron 3369 frame for mortar samples hardened after 28 days measured mechanical properties.

Thermal conductivity measurements [1] were performed through a heat flow meter in "single sample in a double configuration" (NETZSCH heat flow meter HFM 436/0/1). The specimens for the thermal test, after 28 days of hardening, were placed in an oven at a temperature of $60{ }^{\circ} \mathrm{C}$ until a constant mass was reached and then the density [16] was calculated, a parameter to be inserted before starting the test as an input in the Q-Lab software to calculate $\lambda$. The sample tested was placed between two plates placed at two different temperatures $\left(\Delta \mathrm{T}=20^{\circ} \mathrm{C}\right)$ with an average temperature of equilibrium of the tests set at $10^{\circ} \mathrm{C}$.

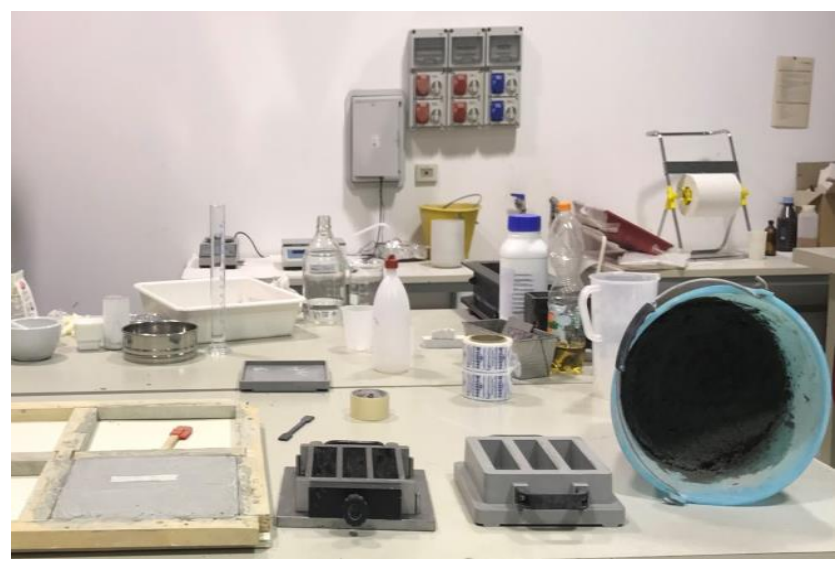

Figure 3. Materials used for the PVC mortar production

Water absorption is a crucial property for construction materials, because influences its durability. Capillary water absorption coefficient was determined according to UNI EN 1015-18:2004 [17]. After 28 days of wet curing, the four long faces of the prismatic specimens were sealed with the paraffin and then they were broken into two halves.

After this step they were oven dried up to constant mass at $60{ }^{\circ} \mathrm{C}$ and finally immersed in a shallow bath of water at a temperature equal to $20^{\circ} \mathrm{C}$ and at a depth of about $6 \mathrm{~mm}$ [1].

Considering mass variation, the capillary absorption coefficient was calculated for all the investigated mortars using a procedure alternative [18] to UNI EN 1015-18:2004. 


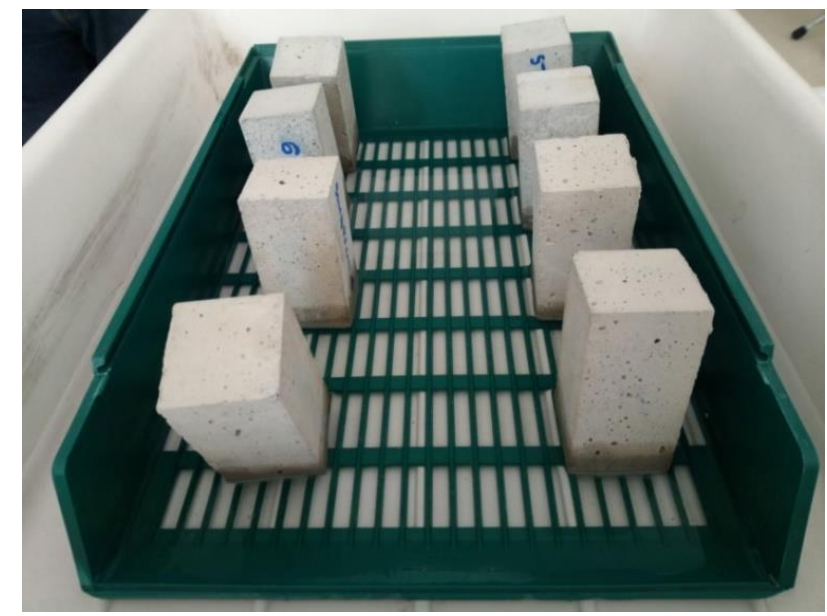

Figure 4. Specimens at minute $t_{10}$

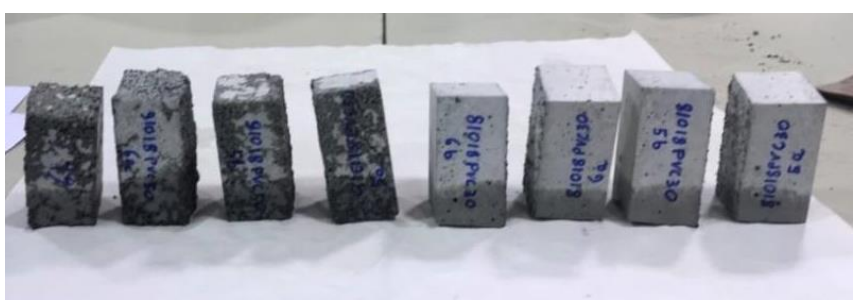

Figure 5. PVC30 and PVC50 specimens at $\mathrm{t}_{120}$

In particular the uptake of water by capillary absorption was measured through the weight gain of each specimen at regular intervals of immersion (10, 30, 45, 90, 120 minutes). The equation used to model the absorption of water due to capillary action is the following:

$$
A=\left(a_{0}+S t^{0.5}\right)
$$

where:

$A\left[\mathrm{mg} / \mathrm{mm}^{2}\right]$ is the water absorbed by the area unit from the moment it is immersed in water;

$S\left[\mathrm{mg} /\left(\mathrm{mm}^{2} \times \mathrm{min}^{0.5}\right)\right]$ is the sorptivity of the material;

$\mathrm{t}$ [minutes] is the elapsed time;

$a_{0}\left[\mathrm{mg} / \mathrm{mm}^{2}\right]$ is the water initially absorbed by the pores in contact with water.

\subsection{PVC-tiles for external flooring}

\subsubsection{Specimen preparation}

For the manufacturing of the urban PVC tiles a standard mix design was set, consisting of $90 \%$ of PVC powder and $10 \%$ of polyurethane resin.

These quantities have been fixed in order to obtain a density of the finished product as close as possible to the density of the reference one. This allowed us to focus attention on optimizing the conditions of pressure and surface temperature to be applied in the curing phase.

The preparation of the compound took place through the mixing of components consisting of the Secondary Raw Material of PVC powder and a thermosetting polyurethane resin. The mixing phase was carried out in three different steps to ensure a more homogeneous and uniform mix.

The polymerization phase was carried out using a double heating plate heat press.

The process for the realization of the compound (Resin + PVC powder) and for the preparation of the formwork was standardized and repeated in the same way during all the test sets.

After some tests, the surface temperature of the two plates was set to a $120^{\circ} \mathrm{C}$, keeping the pressure stable around 50 bar, in order to avoid the problems of denaturation and degradation of the polyurethane resin.

In order to overcome the problems related to the detachment phase, a non-stick silicon-based device with micrometric dimensions (baking paper) was introduced into the system, which perfectly solved the problems of detachment of the specimen once curing was completed.

At the end of the curing phase the specimen was satisfactory both in terms of surface flaking, and in terms of density reached, and in terms of size $(20 \times 20 \mathrm{~cm})$.

However, the final product maintained adequate mechanical strength and surface abrasion.

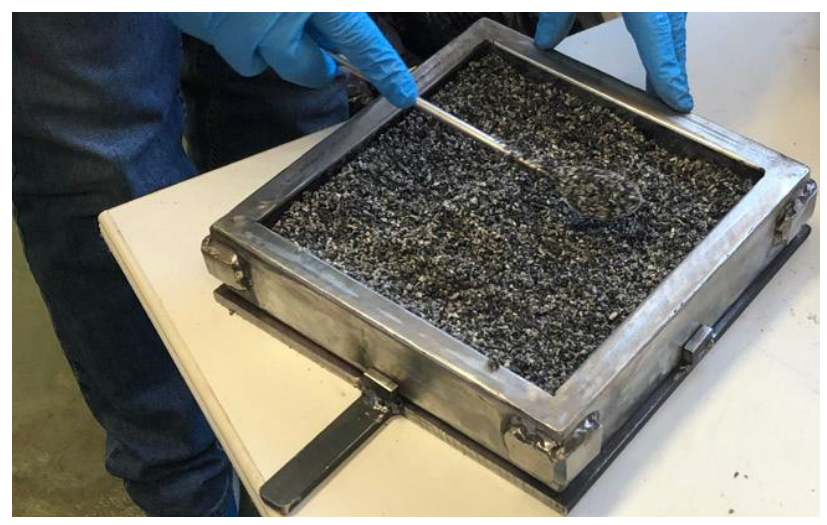

Figure 6. Steel formwork developed for the production of $20 \times 20 \mathrm{~cm}$ tiles



Figure 7. Double hot plate heat press type: 200/20

From a $196 \times 196 \times 10.5 \mathrm{~mm}$ tile, 17 specimens were made for accelerated light stability and weathering tests, whose dimensions are shown in the following table. 
Table 2. Geometric characteristics of the specimens to be subjected to solar aging

\begin{tabular}{lccc}
\hline & Length [mm] & Width [mm] & Thickness [mm] \\
\hline REF1 & 197 & 24.9 & 10.3 \\
\hline REF2 & 196 & 25 & 10.3 \\
\hline REF3 & 195 & 24.9 & 10 \\
\hline REF4 & 196 & 24.4 & 10.5 \\
\hline REF5 & 197 & 25 & 10.3 \\
\hline REF6 & 196 & 24.3 & 10.7 \\
\hline REF7 & 195 & 24.8 & 10.7 \\
\hline A_1 & 195 & 24.7 & 10.4 \\
\hline A_2 & 195 & 24.6 & 10.2 \\
\hline A_3 & 195 & 24.4 & 10.8 \\
\hline A_4 & 195 & 25 & 11.1 \\
\hline A_5 & 196 & 24.4 & 11 \\
\hline B_1 & 196 & 24.6 & 10.3 \\
\hline B_2 & 195 & 24.7 & 10.9 \\
\hline B_3 & 195 & 24.7 & 9.8 \\
\hline B_4 & 197 & 24.7 & 10.5 \\
\hline B_5 & 196 & 25 & 10.5 \\
\hline
\end{tabular}

2.2.2 Correlation between artificial aging cycles and life of materials on work to optimize sunlight simulation

Most polymeric materials are subject to degradation or oxidation reactions when exposed to solar radiation. Among all the materials, polymers are the most sensitive to radiation damage [19].

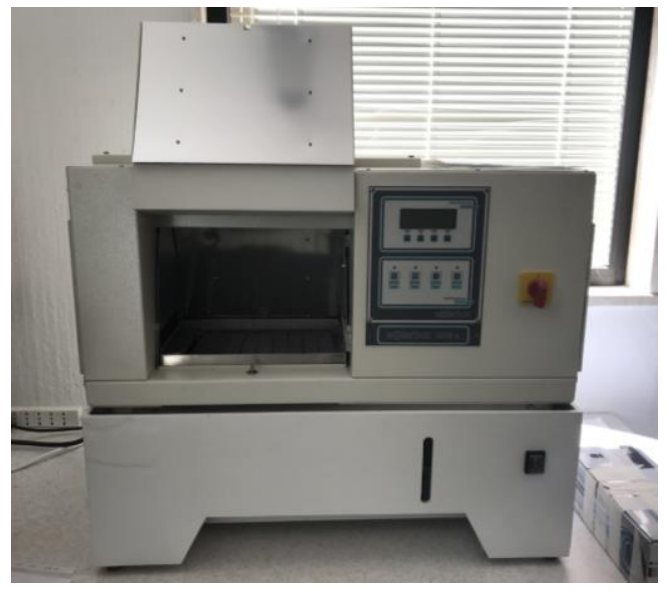

Figure 8. SOLAR BOX 1500E

To simulate solar radiation, a SOLARBOX 1500 E [20] was used, with a flooding system and a Xenon lamp that reproduces the spectral field between 290-800 $\mathrm{nm}$ and a radiant power of between 250 and $1000 \mathrm{~W} / \mathrm{m}^{2}$, making it possible to simulate the entire solar spectrum. Radiant energy in the SOLARBOX is provided by a single superior air-cooled Xenon Lamp generating an irradiance level up to two times the sun one. Irradiance is the rate at which light energy falls onto the samples. A weathering tester must control irradiance if it is to achieve accurate and reproducible test results. SOLARBOX offers constant measurement and control of irradiance during every test, compensating for lamp and UV filter ageing via a closed loop irradiance narrow-band sensor control system. Irradiation uniformity is guaranteed by a parabolic reflector chamber with the Xenon Lamp in the focus, the best design for a reliable flat-bed xenon exposure system and very good agreement with rotating drum xenon exposures.

Heat in the natural environment comes from the infrared portion of natural sunlight. Temperature is another component of the end use environment, which plays a key role in material degradation and is continuously monitored and controlled by a B.S.T. (Black Standard Thermometer).

To develop an experimental campaign of accelerated aging it is necessary to understand which environmental stresses the object under study during its working life.

Being the artifact positioned in Calabria, the data of Southern Italy were used [21].

The graph shows the daily solar radiation in an average year in southern Italy. The total incident solar radiation in an average year is $2387.34 \mathrm{MJ} / \mathrm{m}^{2}$.

The irradiance in the climatic chamber is equal to 1100 $\mathrm{W} / \mathrm{m}^{2}$, so that every hour of aging yields $3.96 \mathrm{MJ} / \mathrm{m}^{2}$ to the samples.

Therefore 600 hours of irradiance provide $2376 \mathrm{MJ} / \mathrm{m}^{2}$, which is the value similar to the solar radiation of an average year.

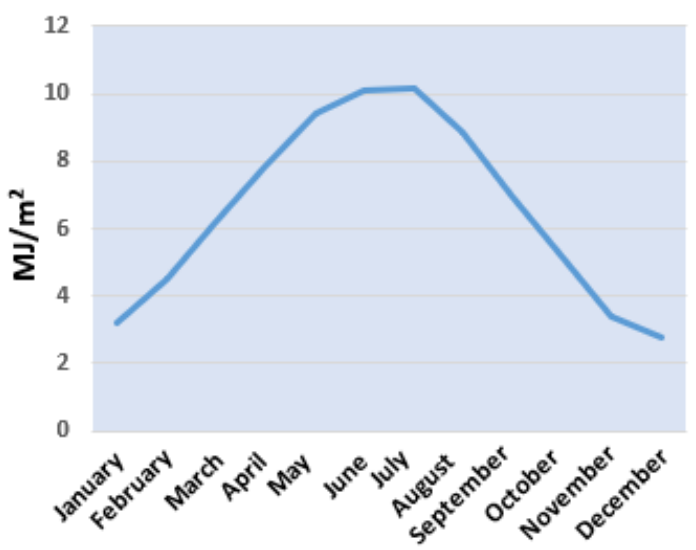

Figure 9. Daily solar radiation in an average year in southern Italy

REF 1 - 7 samples were stored at a temperature of $23{ }^{\circ} \mathrm{C}$ and relative humidity of $60 \%$ in total darkness, while A $1-5$ and B 1 - 5 specimens were aged with the Solar Box 1500e.

The cycle had duration of 600 uninterrupted hours of exposure to the lamp, with a radiation power of $1100 \mathrm{~W} / \mathrm{m}^{2}$ on all the specimens. A $1-5$ specimens were subjected to an aging of 300 hours and then stored in the dark, while B 1 - 5 specimens were subjected to the entire cycle of 600 hours.

\section{RESULTS AND DISCUSSIONS}

\subsection{Mechanical tests}

The flexural and compressive properties for PVC-mortar are presented. It is clear at a first sight that the higher the PVC contents the lower the values of strength [22].

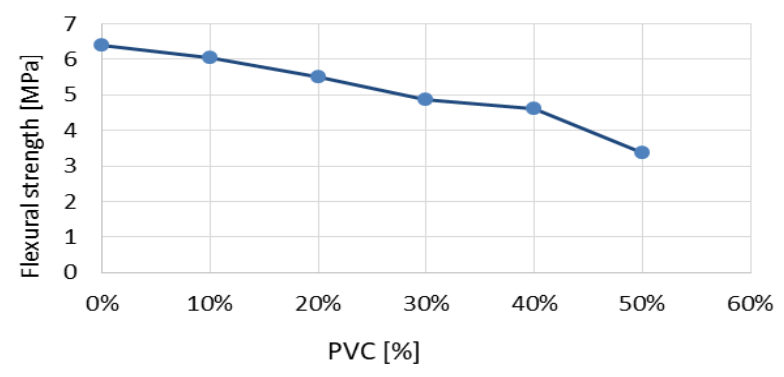

Figure 10. Flexural strength related to PVC percentage 


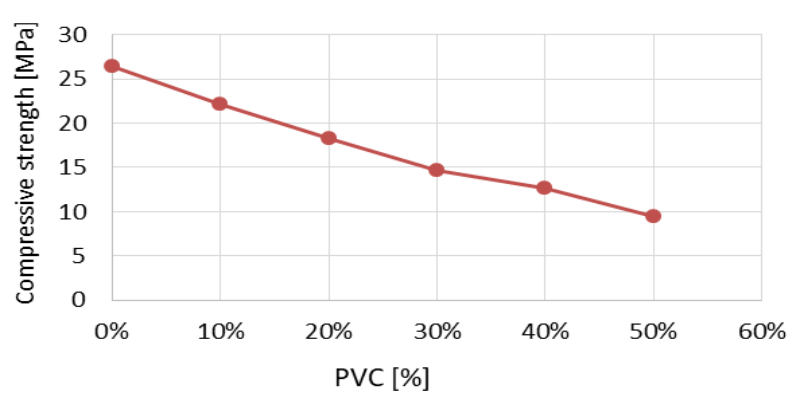

Figure 11. Compressive strength related to PVC percentage

\subsection{Thermal tests}

The thermal conductivity of mortar-plastic compounds samples with different amounts of added recycled PVC is presented. It can be seen that the higher the plastic content in the mixture, the lower the density and the thermal conductivity [23].

In particular with PVC10 and PVC 50 there is a decrease of $6.5 \%$ and $26 \%$, respectively, compared to mortar as it is.

Thermal conductivity $\lambda_{10}[\mathrm{~W} / \mathrm{mK}]$ and thermal resistance $\left[\mathrm{m}^{2} \mathrm{~K} / \mathrm{W}\right]$ were determined for each panel.

Table 3. Thermal properties of the specimens

\begin{tabular}{ccccc}
\hline & REF & PVC10 & PVC30 & PVC50 \\
\hline $\begin{array}{c}\text { Thermal Conductivity } \\
{[\mathrm{W} / \mathrm{mK}]}\end{array}$ & 0.46 & 0.43 & 0.31 & 0.24 \\
\hline $\begin{array}{c}\text { Thermal Resistance }\left[\mathrm{m}^{2}\right. \\
\text { K/W] }\end{array}$ & 0.05 & 0.05 & 0.08 & 0.10 \\
\hline
\end{tabular}

It is very interesting to note that these materials show a remarkable combination of high thermal capacity and relatively low thermal conductivity. Thermal capacity is related with the ability of a material to damp the exterior temperature oscillations (in cold or hot climates) while thermal conductivity (or thermal resistance which is simply the sample thickness divided by conductivity value) measures the capacity of a material as thermal insulator.

This reduction of thermal conductivity values is a very impressive fact given that this adds value to the range of materials under study, so it is worth considering from where the decrease in thermal conductivity arises, in order to expand the test set with other combinations of aggregate as sand replacement.

\subsection{Capillarity water absorption}

Performing the average of the results obtained according to Eq. (1), the capillary adsorption coefficient is calculated by linear interpolation of the values of $A$ and $\mathrm{t}^{0.5}$ and the evaluation of the slope of the curve.

The next graph shows the values of the angular coefficient for each test/class of specimens and the value of $\mathrm{R}^{2}$ calculated with the least squares method [1].

We can see that increasing of plastic content samples led to a decrease of capillary pores and an increase of macroporous structure in the sample volume [24]. Moreover, the hydrophobic nature of polymeric aggregates contributes to slow down the capillary water absorption. As stated, such porous structure is advantageous also for thermal conductivity.

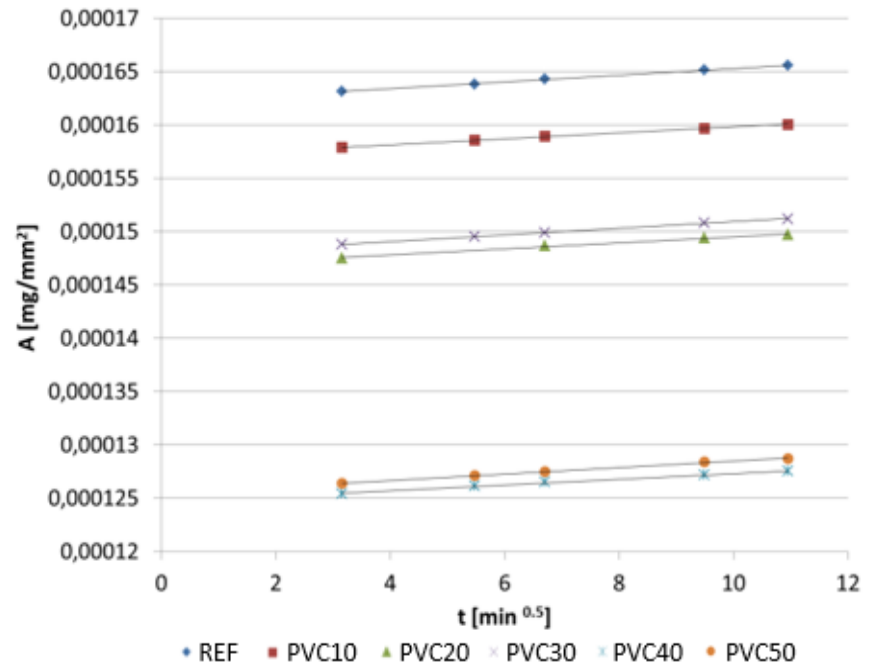

Figure 12. Capillary absorption vs time at different PVC \%

Table 4. Capillary water absorption values

\begin{tabular}{cccccc}
\hline REF & PVC10 & PVC20 & PVC40 & PVC50 & \\
\hline 3.155 & 2.79 & 2.823 & 2.69 & 2.64 & $\begin{array}{c}{\left[\mathrm{kg} /\left(\mathrm{m}^{2} \times\right.\right.} \\
\left.\min ^{0.5}\right]^{*} 10^{4}\end{array}$ \\
\hline- & -11.6 & -10.5 & -14.7 & -16.3 & $\%$ variation $[-]$ \\
\hline
\end{tabular}

\subsection{Degradation of PVC by UV light}

UV radiation causes photooxidative degradation, which results in breaking of the polymer chains, leading to deterioration of mechanical properties and useless materials, after an unpredictable time [25].

\subsubsection{Visual and colorimetric analysis}

The visual analysis consisted in examining the photographs of the specimens, made by a Nikon D5300 reflex camera with a lens with a focal length of $50 \mathrm{~mm}$. The photos were saved in RAW owner Nikon.
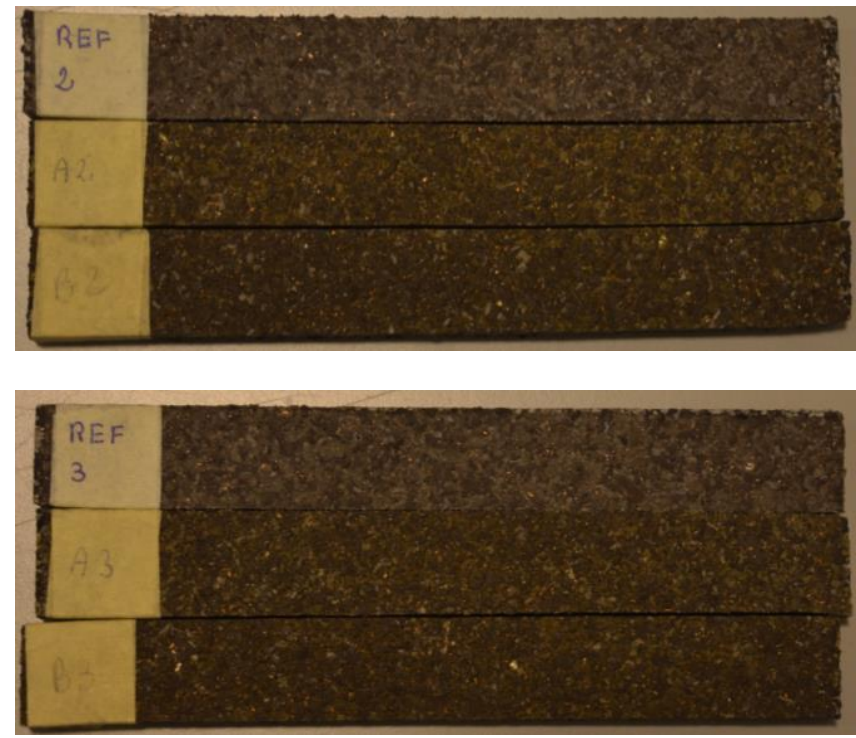

Figure 13. Comparison between not aged and aged specimens 
There is a change in color between the non-aged reference specimens (REF 2 and REF 3), compared to the aged ones, both regarding those subjected to the aging cycle of 600 hours (B2 and B3) and those subjected to the aging cycle of 300 hours (A2 and A3).

The colour becomes increasingly yellow due to the effect of UV radiation. The specimens, however, don't have defects such as cracks, delaminations, material detachments [26].

The colorimetric analysis aims to carry out a quantitative measurement of colour. In the scientific literature various methods have been developed to carry out this measurement; each of these refers to a colour model [27].

The most common models are the HSB (hue, saturation, brightness), the RGB (red, green, blue), the CMYK (cyan, magenta, yellow, black) and the CIE L*a*b*. In the analyses carried out on specimens the CIE L*a*b method was used [28].

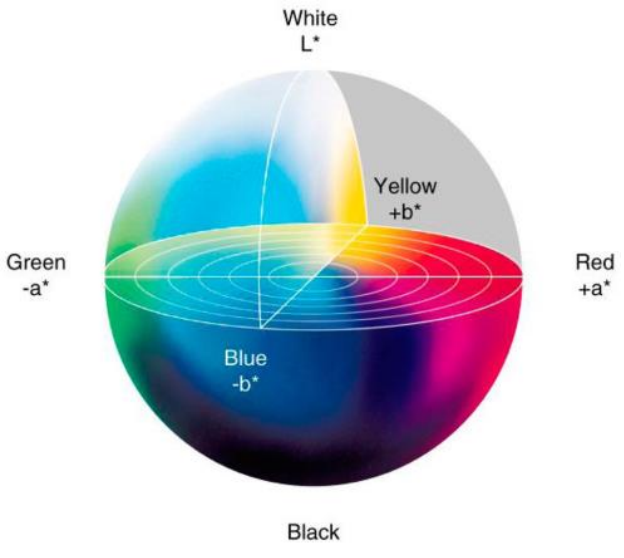

Figure 14. The CIE L * a *b colour space

On the specimens made, colorimetric analyses were performed with the X-Rite SP98 colorimeter at the end of each experimental accelerated aging test. For each specimen 5/7 points were chosen randomly and an average of the values measured with the $\mathrm{L}^{*} \mathrm{a} * \mathrm{~b}$ method was performed.

The $L^{*} a * b$ values measured for each specimen subjected to accelerated aging were compared with the values measured on the sample just manufactured.

The $\Delta \mathrm{E}[29]$, i.e. the difference between two colours, is the criterion for evaluating colour change.

The $\Delta \mathrm{E}$ we used is that of 1994 which is defined [30]:

$$
\Delta E=\sqrt{\left(\frac{\Delta L}{K_{L} S_{L}}\right)^{2}+\left(\frac{\Delta C}{K_{C} S_{C}}\right)^{2}+\left(\frac{\Delta H}{K_{H} S_{H}}\right)^{2}}
$$

$$
\begin{aligned}
& \Delta L=L_{1}-L_{2} \\
& \Delta C=C_{1}-C_{2} \\
& \Delta H=\sqrt{\Delta a^{2}+\Delta b^{2}-\Delta C^{2}} \\
& C_{1}=\sqrt{a_{1}{ }^{2}+b_{1}^{2}} \\
& C_{2}=\sqrt{a_{2}{ }^{2}+b_{2}{ }^{2}} \\
& \Delta a=a_{1}-a_{2} \\
& \Delta b=b_{1}-b_{2} \\
& S_{L}=1 \\
& S_{C}=1+K_{1} C_{1} \\
& S_{u}=1+K_{2} C_{1}
\end{aligned}
$$

$$
\begin{aligned}
K_{L} & = \begin{cases}1 & \text { default } \\
2 & \text { fabrics }\end{cases} \\
K_{C} & =1 \text { default } \\
K_{u} & =1 \text { default } \\
K_{1} & = \begin{cases}0.045 & \text { graphic arts } \\
0.048 & \text { fabrics }\end{cases} \\
K_{2} & = \begin{cases}0.015 & \text { graphic arts } \\
0.014 & \text { fabrics }\end{cases}
\end{aligned}
$$

Figure 15. Expression and calculation of $\Delta \mathrm{E}$
The following table shows the average values of $\Delta \mathrm{E}$ between the colours of the not aged samples with respect to the colour of the aged ones at different aging intervals.

Table 5. $\Delta \mathrm{E}$ values

\begin{tabular}{ccccc}
\hline Specimen typology & $\mathbf{3 0 0} \mathrm{h}$ & $\mathbf{4 0 0 h}$ & $\mathbf{5 0 0} \mathrm{h}$ & $\mathbf{6 0 0 ~ h}$ \\
\hline $\mathrm{A}$ & 4.16 & - & - & - \\
\hline $\mathrm{B}$ & 3.88 & 5.67 & 8.21 & 8.99 \\
\hline
\end{tabular}

It is immediately evident that the colour variations increase with the aging time.

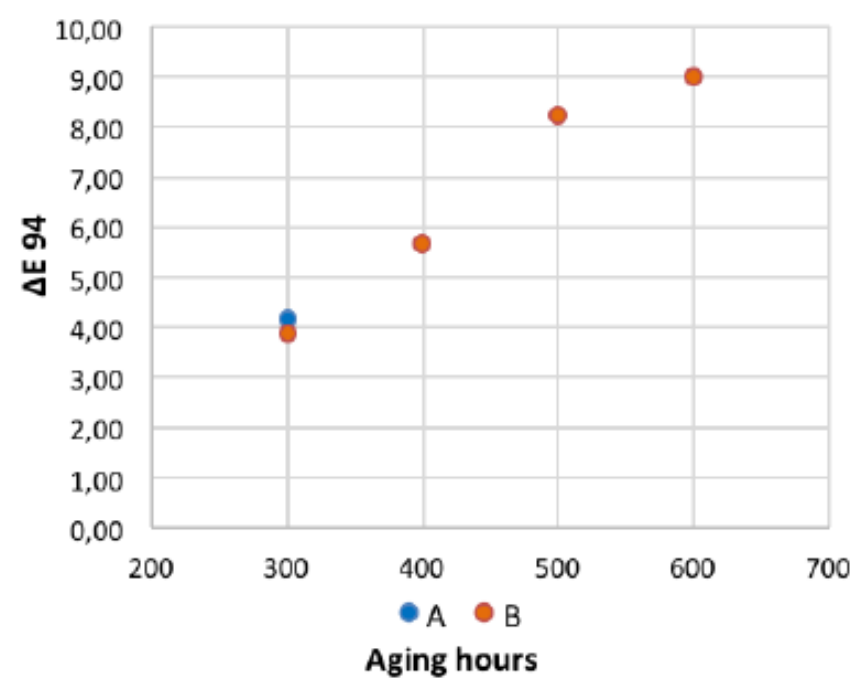

Figure 16. $\Delta \mathrm{E}$ variation according to the aging hours

\subsubsection{Mechanical tests}

Two types of mechanical tests were performed on the specimens: the flexibility test [31] and the flexural test [32]. The test equipment for both types of mechanical tests was the same used before, a Dual Column Instron 3369 frame.



Figure 17. Load scheme for flexibility and flexural tests

In the first case a 3-point flexural test accessory was used. The principle of the test consists in the deformation of the specimen with a cylinder with a curvature much greater than the thickness of the same, by means of a force centred between two fixed supports.

The central load is lowered on the specimen at a speed of $100 \mathrm{~mm} / \mathrm{min}$ until it reaches $15 \mathrm{~mm}$ of lowering. 


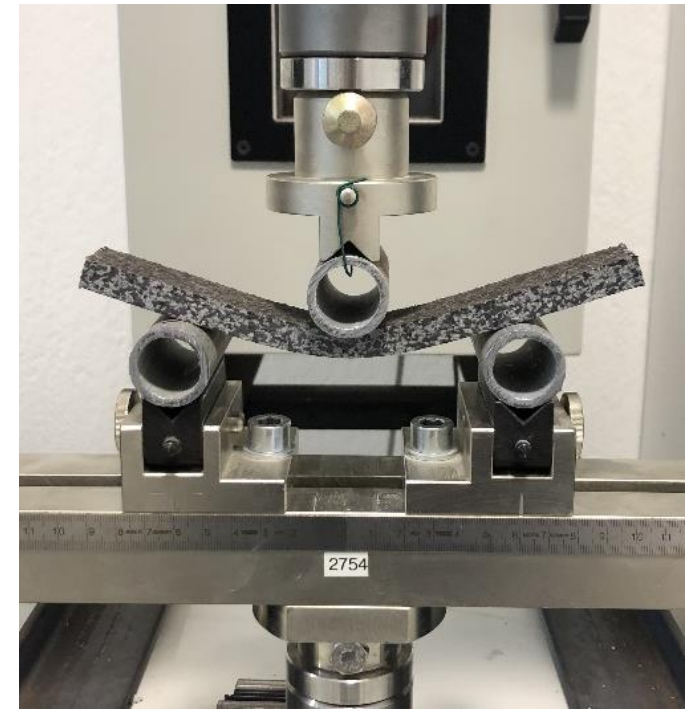

Figure 18. Specimen during a three points flexibility test

All the specimens, both the non-aged and the aged ones, resisted to the deformation (except for one of the 600-hour specimens), presenting no breakage and/or surface cracking.

After the flexibility test all the whole specimens were subjected to the flexural test with a load at a constant speed of $10 \mathrm{~N} / \mathrm{s}$ until breakage.

The following table shows the average load values at breakage of the specimens.

The flexural strength was calculated according to the Standard:

$$
f=\frac{3}{2} \frac{F \cdot l}{b \cdot d^{2}}
$$

where, $F$ is the load in N, $l$ is the distance between the supports, $b$ is the width of the specimen and $d$ is the thickness.

Table 6. Results of flexural tests

\begin{tabular}{ccc}
\hline & Flexural strength [MPa] & $\left(\mathbf{f}-\mathbf{f}_{\text {REF }}\right) / \mathbf{f}_{\text {REF }}[\%]$ \\
\hline REF & 5.52 & -- \\
\hline A & 4.85 & -12 \\
\hline B & 4.61 & -5 \\
\hline
\end{tabular}

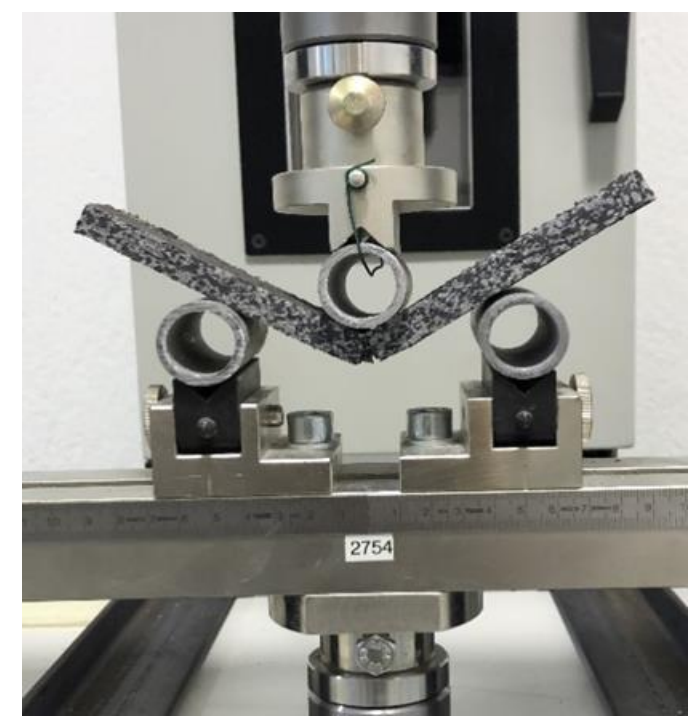

Figure 19. Specimen during a three point flexural test
The flexural strength of the specimens decreases with the aging time. It should be noted that the mechanical resistance decreases in the first 300 hours $(12 \%)$ in a decidedly higher quantity than the subsequent $300(5 \%)$, a typical behaviour of most thermoplastic polymers subjected to solar aging [33].

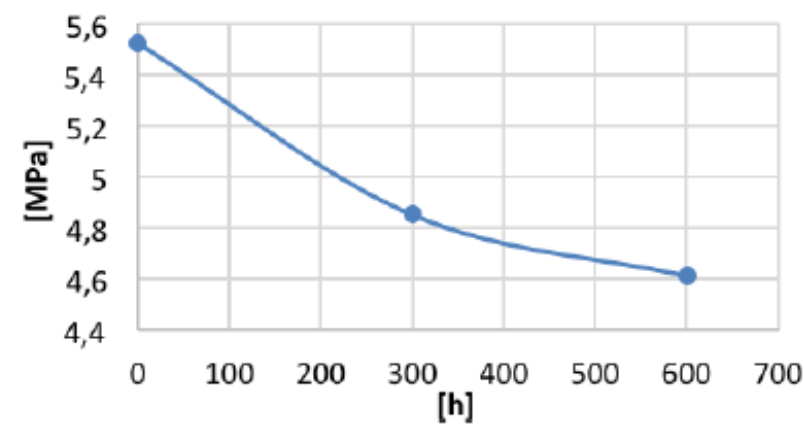

Figure 20. Flexural test related to the aging hours

\section{CONCLUSIONS}

End-of-waste PVC aggregates from electrical cables were managed according to the procedure described in the previous article [1] in a three-step process: recycling, grinding and sieving.

Starting from this second raw material, in addition to PVCmortar for lightweight building applications, a new experimental product was designed and manufactured: PVCurban tile for green parking.

PCV can be better utilized in one of the most consumed building construction material namely concrete instead of being transported to the landfill for the final disposal as an effort to reduce the environmental pollution caused by post consumer plastic wastes along with receiving the benefit of hygro-thermal and durability attributes.

Moreover, the main component of concrete is cement, that is not an environment friendly material because emits big amount of carbon dioxide $\left(\mathrm{CO}_{2}\right)$ during production process: for each ton of cement clinker approximately we have the release of one ton of $\mathrm{CO}_{2}$ and other greenhouse gases (GHGs) to the atmosphere causing global warming.

It appears that all the mortars prepared by substitution of natural aggregate with recycled plastic one show a thermal conductivity coefficient lower than the reference mortar. The thermal conductivity of materials depends upon many factors, including material mixture proportioning, type of aggregate inclusions, density and porosity [34]. In particular porosity plays an important part in heat transfer, because the pores contain air, which has a thermal conductivity $(0.024 \mathrm{~W} / \mathrm{mK})$ much lower than all the other components of the mortar. So mortars containing plastic aggregates will have better thermal insulation properties than convectional ones, which can be used to control heat loss from building during winter and heat gain during summer. This reduction of thermal conductivity is due also to the low density, which depends on one hand to the presence of plastic aggregates and on the other to the increased induced porosity. This is an interesting reduction in civil engineering field where the potential amount of materials needed is huge.

Even though the replacement of the siliceous aggregate with PVC residues leads to a decrease in mechanical properties (because of the very low binding strength between the surface of the plastic particles and the cement paste), opportunities in 
the use of these materials are not affected, especially for applications that do not required a structural function.

To obtain an explicit knowledge of the topic, future investigations should be oriented to the study of microstructure and of the durability performance of mortar containing plastic aggregates.

However, the reduction of water absorption by capillarity together with data existing in literature [35] indicate that the incorporation of various types of plastic aggregate can improve the permeability behavior of cement based composites make them more durable in the face of aggressive chemical attack and effect of weathering environment.

As regards to this aspect, one important objective of the work was to obtain general information regarding the degradation processes in external PVC floorings exposed to the UV-radiation, such as chain scission and colour change (yellowing). The mechanical behavior is affected by the macromolecular changes produced by the accelerated solar aging, as observed in the two kind of mechanical tests. Respect to the control one, after two cycles of artificial solar exposition, the material shows a decrease in resistance less than $12 \%$, that is an acceptable range for the intended use.

All the test results showed good agreement with the observations made by other researchers worked with PVC, PET, PP, PE based recycled powder [36].

These new ecological composites would appear to offer an attractive low-cost material with consistent properties; moreover, they do not involve high-energy consumption and recover the embodied energy of reused PVC, with beneficial effects regarding disposal of solid waste, reduction of raw material use and sustainable development.

\section{REFERENCES}

[1] Cardinale, T., Sposato, C., Alba, M.B., Feo, A., Grandizio, F., Lista, G.F., Montesano, G., De Fazio, P. (2019). Energy and mechanical characterization of composite materials for building with recycled PVC. TECNICA ITALIANA-Italian Journal of Engineering Science, 63(2-4): 129-135. https://doi.org/10.18280/tiijes.632-403

[2] Ismail, Z.Z., Al-Hashmi, E.A. (2008). Use of plastic waste in concrete mixture as aggregate replacement. Waste Manage, 28(11): 2041-2047. https://doi.org/10.1016/j.wasman.2007.08.023

[3] Siddique, R., Khatib, J., Kaur, I. (2008). Use of recycled plastic in concrete: A review. Waste Manage, 28(10): $1835-1852$.

https://doi.org/10.1016/j.wasman.2007.09.011

[4] Soroushian, P., Plasenci, J., Ravanbakhsh, S. (2003). Assessment of reinforcing effects of recycled plastic and paper in concrete. ACI Materials Journal, 100(3): 203 207.

[5] Marzouk, O.Y., Dheilly, R.M., Queneudec, M. (2007). Valorisation of post-consumer plastic waste in cementitious concrete composites. Waste Manage, 27(2) 310-318. https://doi.org/10.1016/j.wasman.2006.03.012

[6] Aciu, C., Ilutiu-Varvara, D.A., Manea, D.L., Orbana, Y.A., Babota, F. (2018). Recycling of plastic waste materials in the composition of ecological mortars Procedia $\quad$ Manufacturing, 22: 274-279. https://doi.org/10.1016/j.promfg.2018.03.042

[7] Ruiz-Herrero, J.L., Velasco Nieto, D., López-Gil, A.,
Arranz, A., Fernández, A., Lorenzana, A., Merino, S., De Saja, J.A., Rodríguez-Pérez, M.Á. (2016). Mechanical and thermal performance of concrete and mortar cellular materials containing plastic waste. Construction and Building Materials, 104: 298-310. http://dx.doi.org/10.1016/j.conbuildmat.2015.12.005

[8] López, A., de Marco, I., Caballero, B.M., Laresgoiti, M.F., Adrados, A. (2011). Dechlorination of fuels in pyrolysis of PVC containing plastic wastes. Fuel Proc. Tech., $\quad$ 92(2): 253-260. https://doi.org/10.1016/j.fuproc.2010.05.008

[9] Choi, B., Yoo, S., Park, S. (2018). Carbon footprint of packaging films made from LDPE, PLA, and PLA/PBAT blends in South Korea. Sustainability, 10(2369): 1-13. https://doi.org/10.3390/su10072369

[10] UNI EN 933-1:2012. Prove per determinare le caratteristiche geometriche degli aggregati - Parte 1: Determinazione della distribuzione granulometrica Analisi granulometrica per setacciatura.

[11] UNI EN 197-1:2011. Cemento - Parte 1: Composizione, specificazioni e criteri di conformità per cementi comuni.

[12] UNI EN 13139: 2002 (cat.0/4). Aggregati per malta.

[13] Thorneycroft, J., Orr, J., Savoikar, P., Ball, R.J. (2018). Performance of structural concrete with recycled plastic waste as a partial replacement for sand. Construction and Building Materials, 16: 63-69. https://doi.org/10.1016/j.conbuildmat.2017.11.127

[14] UNI EN 1015-11:2001. Metodi di prova per malte per opere murarie - Determinazione della resistenza a flessione e a compressione della malta indurita.

[15] UNI EN 12664:2001. Thermal performance of building materials and products - Determination of thermal resistance by means of guarded hot plate and heat flow meter methods - Dry and moist products of medium and low thermal resistance.

[16] UNI EN 1015-10:2007. Metodi di prova per malte per opere murarie - Parte 10: Determinazione della massa volumica apparente della malta indurita essiccata.

[17] UNI EN 1015-18:2004. Metodi di prova per malte per opere murarie - Determinazione del coefficiente di assorbimento d'acqua per capillarità della malta indurita.

[18] Candamano, S., De Luca, P., Frontera, P., Crea, F. (2017) Production of geopolymeric mortars containing forest biomass ash as partial replacement of metakaolin. Environments, $4(4)$ :

74. https://doi.org/10.3390/environments4040074

[19] Yu, J., Sun, L., Ma, C., Qiao, Y. (2016). Thermal degradation of PVC: A review. Waste Management, 48(19): 300-314. 10.1016/j.wasman.2015.11.041

[20] SOLARBOX A family of two sizes and four models tabletop xenon test chambers. http://www.cofomegra.it/www.cofomegra.it/documents/ SOLARBOX_Depliant.pdf, accessed on July 12, 2019.

[21] Petrarca, S., Spinelli, F., Cogliani, E., Mancini, M. (1990). Profilo climatico dell'Italia. Edizioni ENEA.

[22] Iucolano, F., Liguori, B., Caputo, D., Colangelo, F., Cioffi, R. (2013). Recycled plastic aggregate in mortars composition: Effect on physical and mechanical properties. Materials and Design, 52: 916-922. http://dx.doi.org/10.1016/j.matdes.2013.06.025

[23] Latroch, N., Benosman, A.S., Bouhamou, N.E., Senhadji, Y., Mouli, M. (2018). Physico-mechanical and thermal properties of composite mortars containing lightweight aggregates of expanded polyvinyl chloride. Construction 
and Building Materials, 175: 77-87. https://doi.org/10.1016/j.conbuildmat.2018.04.173

[24] Coppola, B., Courard, L., Michel, F., Incarnato, L., Scarfato, P., Di Maio, L. (2018). Hygro-thermal and durability properties of a lightweight mortar made with foamed plastic waste aggregates. Construction and Building Materials, 170: 200-206. https://doi.org/10.1016/j.conbuildmat.2018.03.083

[25] Yousif, E., Hasan, A. (2015). Photostabilization of poly(vinyl chloride) - Still on the run. Journal of Taibah University for Science, 9: 421-448. https://doi.org/10.1016/j.jtusci.2014.09.007

[26] Tang, C.C., Chen, H.I., Brimblecombe, P., Lee, C.L., (2018). Textural, surface and chemical properties of polyvinyl chloride particles degraded in a simulated environment. Marine Pollution Bulletin, 133: 392-401. https://doi.org/10.1016/j.marpolbul.2018.05.062

[27] Pauli, H. (1976). Proposed extension of the CIE recommendation on "Uniform color spaces, color difference equations, and metric color terms". Journal of the Optical Society of America, 66(8): 866-867. https://doi.org/10.1016/j.marpolbul.2018.05.062

[28] Robertson, A.R. (1990). Historical development of CIE recommended color difference equations. Color Res. Appl., $15:$

$167-170$ https://doi.org/10.1002/col.5080150308

[29] Stokes, M., Brill, M.H. (1992). Efficient computation of $\Delta \mathrm{H}^{*}{ }_{\mathrm{ab}}$. Color Res. Appl., 17: 410-411.

[30] Mokrzycki, W., Tatol, M. (2011). Color difference Delta E - A survey. Machine Graphics and Vision, 20(4): $383-$ 41.

[31] UNI EN ISO 24344:2012. Rivestimenti resilienti per pavimentazioni - Determinazione della flessibilità e della deformazione.

[32] UNI ISO 178. Plastics - Determination of flexural properties.

[33] Hare, C.H. (1992). The degradation of coatings by ultraviolet light and electromagnetic radiation. Anatomy of Paint, Materials Technology Section. Journal of

Protective Coatings \& Livings.

[34] Fraj, A.B., Kismi, M., Mounanga, P. (2010). Valorization of coarse rigid polyurethane foam waste in lightweight aggregate concrete. Construction and Building Materials, 24(6): 1069-1077. https://doi.org/10.1016/j.conbuildmat.2009.11.010

[35] Saikia, N., De Brito, J. (2012). Use of plastic waste as aggregate in cement mortar and concrete preparation: A review. Construction and Building Materials, 34: 385401. http://dx.doi.org/10.1016/j.conbuildmat.2012.02.066

[36] Gu, L., Ozbakkaloglu, T. (2016). Use of recycled plastics in concrete: A critical review. Waste Management, 51: 19-42. http://dx.doi.org/10.1016/j.wasman.2016.03.005

\section{NOMENCLATURE}

$\mathrm{F}$

$\mathrm{f}$

d

A

A

$\mathrm{S}$

$\mathrm{a}_{0}$

\section{Greek symbols}

$\lambda$

$\Delta \mathrm{T}$

$\Delta \mathrm{E}$ maximum load applied, $\mathrm{N}$ flexural strength, N.mm ${ }^{-2}$ thickness of the specimen, $\mathrm{mm}$ distance between the axes of the support rollers, $\mathrm{mm}$

capillarity water absorption coefficient, $\mathrm{kg} \cdot \mathrm{m}^{-2} \cdot \mathrm{min}^{-0.5}$ )

time, $\min$

water absorbed by the area unit from the moment it is immersed in water, mg. $\mathrm{mm}^{-}$

material sorptivity, $\mathrm{mg} \cdot \mathrm{mm}^{-2} \cdot \mathrm{min}^{-0.5}$ water initially absorbed by the pores in contact with water, mg. $\mathrm{mm}^{-2}$

thermal conductivity, W. $\mathrm{m}^{-1} \cdot \mathrm{K}^{-1}$ temperature difference between the two faces of the test, $\mathrm{K}$ colour change coefficient 